\title{
Impact of Plasmodium falciparum infection on haematological parameters in children living in Western Kenya
}

Robert N Maina ${ }^{1,2}$, Douglas Walsh ${ }^{1,2}$, Charla Gaddy ${ }^{1,2}$, Gordon Hongo ${ }^{1,2}$, John Waitumbi ${ }^{1,2}$, Lucas Otieno ${ }^{1,2}$, David Jones ${ }^{1,2}$, Bernhards R Ogutu ${ }^{1,2,3^{*}}$

From 5th Multilateral Initiative on Malaria Pan-African Malaria Conference

Nairobi, Kenya. 2-6 November 2009

\begin{abstract}
Background: Malaria is the commonest cause of childhood morbidity in Western Kenya with varied heamatological consequences. The t study sought to elucidate the haemotological changes in children infected with malaria and their impact on improved diagnosis and therapy of childhood malaria.

Methods: Haematological parameters in 961 children, including 523 malaria-infected and 438 non-malaria infected, living in Kisumu West District, an area of malaria holoendemic transmission in Western Kenya were evaluated.

Results: The following parameters were significantly lower in malaria-infected children; platelets, lymphocytes, eosinophils, red blood cell count and haemoglobin ( $\mathrm{Hb})$, while absolute monocyte and neutrophil counts, and mean platelet volume (MPV) were higher in comparison to non-malaria infected children. Children with platelet counts of $<150,000 /$ uL were 13.8 times (odds ratio) more likely to have malaria. Thrombocytopaenia was present in $49 \%$ of malaria-infected children and was associated with high parasitaemia levels, lower age, low Hb levels, increased MPV and platelet aggregate flag. Platelet aggregates were more frequent in malaria-infected children ( $25 \%$ vs. $4 \%, p<0.0001)$ and associated with thrombocytopaenia rather than malaria status.
\end{abstract}

Conclusion: Children infected with Plasmodium falciparum malaria exhibited important changes in some haematological parameters with low platelet count and haemoglobin concentration being the two most important predictors of malaria infection in children in our study area. When used in combination with other clinical and microscopy, these parameters could improve malaria diagnosis in sub-patent cases.

\section{Background}

Blood is the most easily accessible diagnostic tissue. Changes in haematological parameters are likely to be influenced by any disease condition which affects the haemopoetic physiology at any level. This is likely to happen with an endemic disease such as malaria that affects the host homeostasis at various fronts resulting in a myriad of clinical presentation. Malaria is a major cause of morbidity in the tropics. Two hundred and forty seven million cases were reported worldwide in

\footnotetext{
* Correspondence: bogutu@wrp-ksm.org

'US Army Medical Research Unit-Kenya (Walter Reed Project), Nairobi, Kenya Full list of author information is available at the end of the article
}

2006 [1]. Haematological changes are some of the most common complications in malaria and they play a major role in malaria pathology. These changes involve the major cell lines such as red blood cells, leucocytes and thrombocytes. In Western Kenya, severe anaemia is the predominant severe malaria syndrome peaking in the first two years of life and is attributed to Plasmodium falciparum [2]. In malaria-infected patients, especially non-immunes children, prompt and accurate diagnosis is key to effective disease management for a favourable outcome. Clinical diagnosis is widely used for diagnosis of malaria especially in resource-poor countries. Although fever and other signs and symptoms are known to be fairly sensitive measures of malaria they

O

C 2010 Maina et al; licensee BioMed Central Ltd. This is an open access article distributed under the terms of the Creative Commons Attribution License (http://creativecommons.org/licenses/by/2.0), which permits unrestricted use, distribution, and reproduction in any medium, provided the original work is properly cited. 
lack specificity and positive predictive values especially in areas where malaria is less prevalent [3-6]. This is likely to be the scenario with changing epidemiology of malaria in Africa. Moreover, in tropical countries where malaria is most prevalent, it may be difficult to distinguish the disease from other infections e.g. viral or bacterial based on the symptoms and signs [6,7]. Presumptive anti-malarial treatment is widely practiced and studies show that it is wrought with significant misuse of anti-malarial drugs [4,8]. Microscopic diagnosis is the "imperfect gold standard" for malaria parasite detection and speciation. This technique requires technical expertise and is time-consuming in repeated smear examinations [6]. However, it is a valuable technique when performed correctly in the right hands but can be unreliable and perceived as wasteful when poorly executed [7-9]. Haematological changes in malaria, such as anaemia, thrombocytopaenia and leucocytosis or leucopaenia are well recognized. The extent of these alterations varies with level of malaria endemicity, background haemoglobinopathy, nutritional status, demographic factors, and malaria immunity $[3,10,11]$. Furthermore, diagnostic value of these haematological alterations has not been established in children living in malaria endemic areas. The present study examines the occurrences and severity of haematological changes and their diagnostic value in children with P. falciparum malaria in Kisumu, western Kenya. Haematological parameters (red blood cells, white blood cells, platelets, red cell distribution width, mean platelet volume and haemoglobin) of children less than 5 years infected with $P$. falciparum are compared with uninfected children from the same community. In this study, haematological patterns and their possible predictive values of malaria infection are identified.

\section{Methods}

This study was approved by Kenya Medical Research Institute (KEMRI) Scientific Steering Committee and Ethical Review Committee, Walter Reed Army Institute of Research (WRAIR) Scientific Review Committee, US Army Medical Research and Materiel Command (USAMRMC), Human Subjects Research Review Board (HSRRB), and the PATH Human Subject Protection Committee (HSPC). The parents/guardians of the study participants gave a written informed consent before being enrolled into the study. The consent included long-term secure storage of collected samples and information generated during the study and their use for research. The study was conducted at the Kombewa, Kenya Medical Research Institute - US Army Medical research Unit-Kenya (KEMRI/USAMRU-K) Clinical Trails Unit in Kisumu West District of western Kenya an area of intense malaria transmission. The data used in this study were collected during the screening and follow-up phases of a malaria vaccine trial in March December 2005 [12]. The study was reviewed and approved by the Kenya Medical Research Institute's ethical review committee.

Laboratory records of children enrolled in the vaccine trial were reviewed. Nine hundred and sixty one children (age <5yrs) were included in this analysis. This included 523 children diagnosed with P. falciparum malaria and 438 non-malaria infected children from the same community.

The investigations were performed on venous blood sample drawn into EDTA tubes for preparation of the thick and thin smears for malaria parasites and automated determination of Complete Blood Counts (CBCs). Blood counts were performed using ACT5 Diff Haematology Analyzer (Beckman Coulter Inc, Miami, Florida, USA) as per local SOPs within 1 hour.

Daily Quality Assurance checks were performed and recorded; commercial controls were used in accordance with manufacturer's recommendations. The Analyzer provided data on WBCs, RBCs, haemoglobin level, platelet counts, Mean platelet volume, red cell distribution width (RDW) and five part differentials. The Analyzer also detected and flagged as platelet aggregation and cold agglutinins based on the particle size using a 256channel pulse-height analyzer of platelet histogram region.

Two blood slides were prepared and stained with Giemsa. One slide from each study participant was examined independently by two experienced microscopists. They determined presence or absence of malaria parasites, the species and the number of asexual parasites. Parasite enumeration was performed on thick film/ $200 \mathrm{WBCs}$ or thin film/2,000 RBCs, depending on the parasite density. Results of the two primary readers were averaged if concordant and used for the calculation of parasite density. Non-concordance in species or parasite counts between the primary readers was referred to a third microscopist (tie breaker) whose determination of species and parasite count was considered final. Parasite densities were calculated as parasite/ $\mu \mathrm{L}$ of blood (parasite/WBCs counted $x$ total WBCs in a $\mu \mathrm{L}$ of blood or parasite/RBCs counted $x$ total RBCs in a $\mu \mathrm{L}$ of blood). Percent parasitaemia was calculated as follows; parasite count per $\mu \mathrm{L}$ of blood/RBCs per $\mu \mathrm{L} \times 100$. These blood samples were also used for determining the presence of haemoglobinopathies ( $\alpha$-thalassaemia trait, G6PD status and $\mathrm{Hb}$ type).

\section{Data analysis}

Data analysis was performed using GraphPad prism software (GraphPad software, Inc, San Diego Calif.). Normally distributed continuous data were compared using student's t-test with 2 tailed $P$-values, whereas data not 
conforming to normal distribution were compared by Mann-Whitney U test. Categorical variables were compared using Fisher's exact test. Association between two continuous variables was assessed by Spearman's rank correlation. Diagnostic accuracy of haematological parameters was measured by computing sensitivity, specificity, predictive values and odds ratios. Precision of these parameters was evaluated using 95\% confidence intervals.

\section{Results}

Nine hundred and sixty one children were included in this study. The mean age was 32 months (5-48) and $56 \%$ were males. Fifty four percent $(n=523)$ of the subjects had $P$. falciparum malaria confirmed by microscopy while the remaining were negative and were used as controls.

The mean values of selected haematological parameters for the non-malaria infected group (controls) were determined for this population stratified by sex. $\mathrm{T}$-test showed no significant difference in $\mathrm{Hb}$, platelets, total WBCs, RDW, and RBC counts between males and females. As a result, subsequent analysis of continuous variables was not stratified by sex.

Haematological parameters of the malaria parasitemic group were compared with those of the controls using t-test (Mann-Whitney U test). Median values for Haemoglobin, Platelet count, RBC count lymphocyte and eosinophils counts were significantly lower for the parasitemic group compared with the controls. Conversely, the Mean platelet volume (MPV), Monocyte and neutrophil counts were significantly higher in the parasitemic group. There was no significant difference in total WBC and RDW between the parasitemic and the non-parasitemic groups (Table 1).

Table 1 Haematological values in children with positive

\begin{tabular}{llll}
\hline Variable & Malaria, $\boldsymbol{n}=523$ & No malaria, $\boldsymbol{n = 4 3 8}$ & $\boldsymbol{P}$ - Value \\
\hline $\begin{array}{l}\text { Mean } \\
\text { (Median) }\end{array}$ & $\begin{array}{l}\text { Mean } \\
\text { (Median) }\end{array}$ & & \\
Age (months) & $31.2(24)$ & $31.6(24)$ & 0.72 \\
Hemoglobin (g/dl) & $9.5(9.2)$ & $10.9(10.8)$ & $<0.0001$ \\
Platelets $\left(\times 10^{3} / \mu \mathrm{L}\right)$ & $195(174)$ & $334(312)$ & $<0.0001$ \\
RDW (\%) & $16.4(15.9)$ & $16.7(16.4)$ & 0.15 \\
MPV (fl) & $8.43(8.4)$ & $7.65(7.7)$ & $<0.0001$ \\
WBC(x10 $/ \mu \mathrm{L})$ & $11.2(10)$ & $10.4(9.1)$ & 0.27 \\
Lymphocytes $\left(\times 10^{3} / \mu \mathrm{L}\right)$ & $4.7 .(4.2)$ & $5.3(4.95)$ & 0.0009 \\
Monocytes $\left(\times 10^{3} / \mu \mathrm{L}\right)$ & $1.6(1.3)$ & $1.2(1.02)$ & $<0.0001$ \\
RBC (x10 $/ \mu \mathrm{L})$ & $4.0(4.1)$ & $4.7(4.6)$ & $<0.0001$ \\
Neutrophils $\left(\times 10^{3} / \mu \mathrm{L}\right)$ & $3.8(2.8)$ & $3.3(2.6)$ & 0.0076 \\
Eosinophils $\left(\times 10^{3} / \mu \mathrm{L}\right)$ & $0.2(0.14)$ & $0.4(0.23)$ & 0.0001 \\
\hline
\end{tabular}

\section{Haemoglobin}

Anaemia was defined as haemoglobin level $<10 \mathrm{~g} / \mathrm{dl}$ for both males and females and further classified as severe if $\mathrm{Hb} \leq 5 \mathrm{~g} / \mathrm{dl}$. Severe malaria anaemia was consequently defined as $\mathrm{Hb} \leq 5 \mathrm{~g} / \mathrm{dl}$ in the presence of hyperparasitaemia (> 200,000 parasites $/ \mu \mathrm{L}$ ) [13]. The median haemoglobin value of the malaria-infected group was significantly lower than the negative group $(9.2 \mathrm{~g} / \mathrm{dl}$ vs. $10.8 \mathrm{~g} / \mathrm{dl}, P<0.0001)$. Three hundred and twelve $(60 \%)$ of the malaria-infected children had anaemia with $18(3 \%)$ being severe compared to 118 (27\%) in the non-malaria infected group all being mild anaemia. There was poor correlation between parasitaemia and haemoglobin $(\mathrm{r}=-0.08, p=0.78)$.

Of the 112 anaemia cases in the non-malaria infected group, $42 \%$ had some type of haemoglobinopathy (HbAS $=10 \%$, G6PD deficiency $=6 \%$ and mutant $\alpha$-globulin gene $=25 \%)$ compared to $25 \%\left(\mathrm{HbAS}=6 \%, \mathrm{G}^{-} \mathrm{PD}^{-}=4 \%\right.$ and $\alpha^{*}=16 \%$ ) of non anaemic children (Table 2). These cases of haemoglobinopathies are thought to have contributed to the anaemia observed in some of the non-malaria infected children. Haemoglobinopathy data for 310 subjects was not available. Hb level positively correlated with age $(\mathrm{r}=0.24, \mathrm{p}=0.0005)$.

\section{Platelets}

Thrombocytopaenia was defined as platelet count $<150$ $\mathrm{x} 10^{3} / \mu \mathrm{L}$ and further defined as severe if the platelet count $<50 \times 10^{3} / \mu \mathrm{L}$. The median platelet count for the 523 children in the malaria-infected group was significantly lower than non- malaria infected group (174 $\mathrm{x}$ $10^{3} / \mu \mathrm{L}$ vs. $\left.312 \times 10^{3} / \mu \mathrm{L} ; p<0.0001\right)$. Thrombocytopaenia was reported in 255 (49\%) of the malaria-infected

\section{Table 2 Haemoglobin levels and distribution of} haemoglobinopathies in the study groups

\begin{tabular}{|c|c|c|c|c|c|c|c|c|}
\hline \multirow{2}{*}{\multicolumn{2}{|c|}{$\begin{array}{l}\text { No Malaria } \\
n=438\end{array}$}} & \multirow[b]{3}{*}{$\mathrm{HbAS}$} & \multirow[b]{3}{*}{$\mathrm{HbAA}$} & \multirow[b]{3}{*}{ Unknown } & \multirow{2}{*}{\multicolumn{2}{|c|}{$\begin{array}{l}\text { Malaria } \\
n=523\end{array}$}} & \multirow[b]{3}{*}{$\mathrm{HbAA}$} & \multirow[b]{3}{*}{ Unknown } \\
\hline & & & & & & & & \\
\hline Hb level & $\mathrm{N}$ & & & & $\mathrm{n}$ & $\mathrm{HbAS}$ & & \\
\hline$<5 \mathrm{~g} / \mathrm{dl}$ & 0 & 0 & 0 & 0 & 7 & 0 & 1 & 6 \\
\hline $5-10 \mathrm{~g} / \mathrm{dl}$ & 29 & 12 & 10 & 4 & 70 & 24 & 12 & 34 \\
\hline$>10 \mathrm{~g} / \mathrm{dl}$ & 73 & 18 & 47 & 10 & 65 & 20 & 8 & 37 \\
\hline Hb level & $N$ & G6PD- & G6PD & Unknown & $N$ & $\mathrm{G} 6 \mathrm{PD}^{-}$ & G6PD & Unknown \\
\hline$<5 \mathrm{~g} / \mathrm{dl}$ & 0 & 0 & 0 & 0 & 5 & 0 & 0 & 5 \\
\hline $5-10 \mathrm{~g} / \mathrm{dl}$ & 17 & 7 & 6 & 3 & 76 & 19 & 20 & 37 \\
\hline$>10 \mathrm{~g} / \mathrm{dl}$ & 48 & 12 & 31 & 6 & 85 & 8 & 35 & 42 \\
\hline Hb level & $N$ & $\alpha^{*}$ & $\begin{array}{l}\alpha \\
{ }_{2} \alpha_{1} \alpha \\
{ }_{2} \alpha_{1}\end{array}$ & Unknown & $n$ & $\alpha^{*}$ & $\begin{array}{l}a_{2} a_{1} / \\
a_{2} a_{1}\end{array}$ & Unknown \\
\hline$<5 \mathrm{~g} / \mathrm{dl}$ & 0 & 0 & 0 & 0 & 6 & 0 & 1 & 5 \\
\hline $5-10 \mathrm{~g} / \mathrm{dl}$ & 72 & 30 & 31 & 9 & 131 & 68 & 8 & 55 \\
\hline$>10 \mathrm{~g} / \mathrm{dl}$ & 199 & 50 & 122 & 30 & 78 & 47 & 4 & 27 \\
\hline
\end{tabular}

$\mathrm{G} \mathrm{PD}^{-}=$deficient $\mathrm{G6PD}$ activity, $\mathrm{G} 6 \mathrm{PD}=$ normal activity, $\alpha \alpha / \alpha \alpha=$ normal $\alpha$-globulin gene, $\alpha^{*}=$ defective $\alpha$-globulin gene 
children with 25 (5\%) being severe as compared to 16 (4\%) in the non-malaria infected group which had no cases of severe thrombocytopaenia (Table 3).

Thrombocytopaenia was also weekly associated with, anaemia in the malaria infected group $(\mathrm{r}=0.2, P=0.0003)$ and age $(\mathrm{r}=0.14, p=0.0073)$. There was a strong inverse correlation between platelet counts and mean platelet volume (Figure 1). Mean MPV increased as platelet count fell in both malaria infected $(\mathrm{r}=-0.4, p<0.0001)$ and Non-infected $(\mathrm{r}=-0.34, p<0.0001)$ group. There was an inverse relationship between parasitaemia and platelet counts $(\mathrm{r}=-0.44, p<0.0001)$ (Figure 2$)$. Over $50 \%$ of samples with a parasitaemia above $10 \%$ had a platelet count $<50,000 / \mu \mathrm{L}$. A decreasing trend of platelet counts across quartiles of parasite densities was also evident (Table 4).

\section{Platelet count and parasite density}

Parasitaemia levels (\%) ranged from 0.0004 to 29 with a mean of 1.9 (95\% CI, 1.6-2.2). Most children (60\%) had parasitaemia $\leq 1 \%, 157$ (30\%) had values between $1-5 \%$, 37 (7\%) had values between 5.1-10\%, and 17 (3\%) had a parasitaemia $>10 \%$ (Table 4 ). Parasitaemia levels were not affected by gender (median males $1 \%$ vs. Females $1.3 \%, \mathrm{p}=0.47)$. Percent parasitaemia was inversely associated with age $(\mathrm{r}=-0.2, \mathrm{p}=0.0134)$ with younger children having higher parasite densities.

Microscopic examination of peripheral blood smears of malaria positive smears for morphological abnormalities not only confirmed the presence of small platelet aggregates and giant platelets that triggered the platelet aggregate flag, but also revealed monocytes that contained malaria pigments as well as erythrophagocytosed infected red blood cells (Figures 3 and 4)

\section{Platelet aggregation}

Platelet aggregation refers to the clumping together of platelets in the blood and comprises homogenous clusters of 3-12 individual platelets. When present in the blood sample they are detected by the Analyzer on the basis of their size using a 256-channel pulse-height analyzer. Platelet aggregate flag is generated by the Analyzer when platelet aggregation is detected. Significantly more children in the malaria-infected group had platelet aggregation ( $25 \%$ vs. $4 \%, \mathrm{p}<0.0001)$. Stratifying the data by different platelet count revealed an inverse

Table 3 Distribution of platelet counts in the study groups

\begin{tabular}{lll}
\hline Platelet count & $\begin{array}{l}\text { Malaria Positive } \\
\mathbf{N = 5 2 3}\end{array}$ & $\begin{array}{l}\text { Malaria Negative } \\
\mathbf{N}=\mathbf{4 3 8}\end{array}$ \\
\hline$<50 \times 10^{3} / \mu \mathrm{L}$ & $25(5 \%)$ & 0 \\
$<50 \times 10^{3} / \mu \mathrm{L}$ & $230(44 \%)$ & $16(4 \%)$ \\
$151-450 \times 10^{3} / \mu \mathrm{L}$ & $258(49 \%)$ & $356(81 \%)$ \\
$>450 \times 10^{3} / \mu \mathrm{L}$ & $10(2 \%)$ & $66(15 \%)$ \\
\hline
\end{tabular}

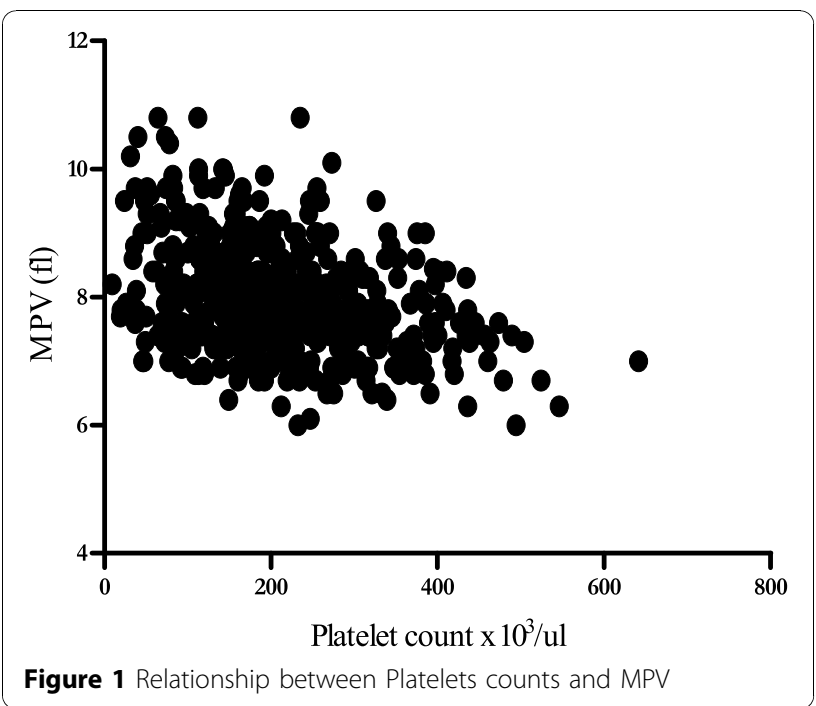

relationship between platelet aggregation and platelet count irrespective of malaria infection status (Table 5). Moreover, difference was not significant between the number of children with thrombocytopaenia and platelet aggregation in the malaria infected group and that of thrombocytopaenic cases with platelet aggregates in non-malaria infected group ( $23 \%$ vs. $18 \%, p=0.6)$. Thirteen percent of children with normal platelet counts had platelet aggregation.

\section{Cold agglutinin}

Cold agglutinins refer to the circulating antibodies directed against own red blood cells and which bind to $\mathrm{RBC}$ at low temperatures. These are detected by the hematology analyzer and the cold agglutinin flag is generated. There was no relationship between the cold agglutinin detection and platelet count. The frequency

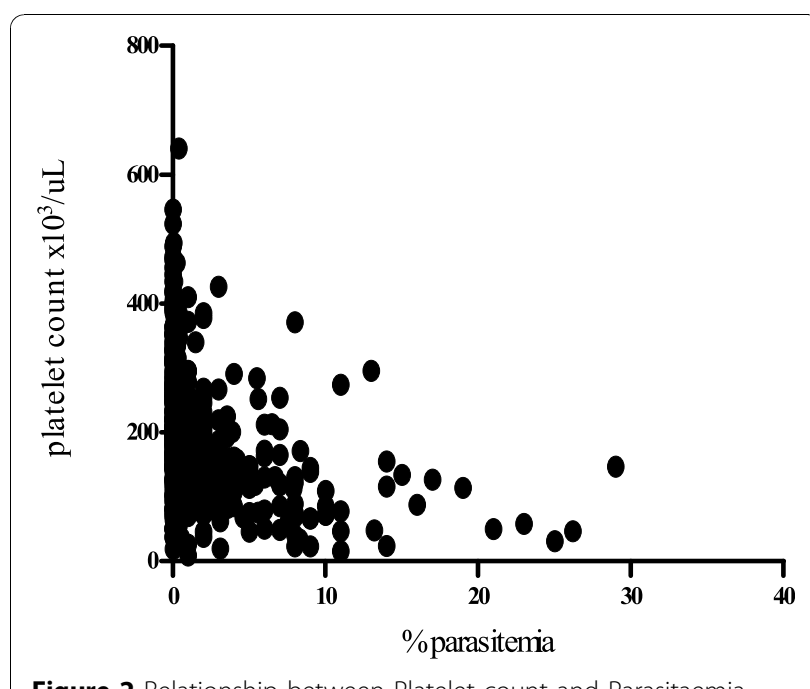


Table 4 Distribution of platelet counts according to parasitaemia levels

\begin{tabular}{|c|c|c|c|c|c|c|}
\hline Parasitemia level & $\mathbf{N}$ & $<50 \times 10^{3} / \mu \mathrm{l}$ & $51-150 \times 10^{3} / \mu \mathrm{l}$ & $151-450 \times 10^{3} / \mu \mathrm{l}$ & $>450 \times 10^{3} / \mu \mathrm{l}$ & Mean platelet count $\times 10^{3} / \mu$ \\
\hline$\leq 1 \%$ & 312 & $3(1 \%)$ & $95(30 \%)$ & $205(66 \%)$ & $9(3 \%)$ & 235 \\
\hline $1.1-5.0 \%$ & 157 & $6(4 \%)$ & 109(69\%) & $41(26 \%)$ & $1(1 \%)$ & 187 \\
\hline $5.1-10 \%$ & 37 & $7(19 \%)$ & 19(51\%) & $11(30 \%)$ & $0 \%$ & 145 \\
\hline$>10 \%$ & 17 & $9(53 \%)$ & $7(41 \%)$ & $1(6 \%)$ & $0 \%$ & 117 \\
\hline Total & 523 & 25 & 230 & 258 & 10 & \\
\hline
\end{tabular}

of cold agglutinins in children with thrombocytopaenia irrespective of malaria infection status (42\%) was comparable with that of children with normal platelet counts (36\%). The presence of cold agglutinins was correlated with malaria infection as $64 \%$ of the children with cold agglutinins also had malaria (Table 6).

\section{White blood cells}

Leucocytosis was defined as total white cell count $>17,000 / \mu \mathrm{L}$. Although leucocytosis was frequently seen in the malaria-infected group than the non-infected group ( $8 \%$ vs. $3 \%, p=0.0028)$, there was no significant difference in total WBC between the two groups (median $10,000 / \mu \mathrm{L}$ vs. $9100 / \mu \mathrm{L}, p=0.27$ ). However leukocyte components were significantly affected. Neutrophil count (median $2,800 / \mu \mathrm{L}$ vs. $2,600 / \mu \mathrm{L}, p=0.0076$ ), monocyte count (median $1,300 / \mu \mathrm{L}$ vs. $1,020 / \mu \mathrm{L}, p<0.0001$ ) were all significantly elevated in the malaria-infected group as compared to the non-malaria infected group. Eosinophil count (median $140 / \mu \mathrm{L}$ vs. $230 / \mu \mathrm{L}, p<0.0001$ ) and lymphocyte count (median $4200 / \mu \mathrm{L}$ vs. $4900 / \mu \mathrm{L}$, $p=0.0009$ ) were significantly reduced in the malariainfected group as compared to the non-infected group (Table 1). Malaria infected children were more likely to have monocytosis (defined as count $\left.>1.5 \times 10^{3} / \mathrm{uL}\right)(39 \%$ vs. $16 \%, p=0.0006)$ compared to those not infected. Malaria infected children were also more likely to have lymphocytopenia defined as count $<2.0 \times 10^{3} / \mathrm{uL}$ compared to the non-infected ones (6\% vs. $1.5 \%, p=0.0016)$.
Monocyte count was positively correlated with parasite density $(\mathrm{r}=0.23, p=0.0003)$ and negatively with age $(\mathrm{r}=-0.15, p=0.0042)$. There was no demonstrable relationship between total WBC, neutrophil or lymphocyte counts with parasite densities or age.

\section{Diagnostic values of haematological parameters}

Low lymphocyte, high WBC and high neutrophil counts had fairly good sensitivities but lacked specificity to accurately diagnose malaria. Low platelet count, low haemoglobin and high monocyte counts had better sensitivities and specificity for diagnosis of malaria. These parameters also had better odds ratios. Children with platelet $<150,000 / \mathrm{uL}$ were up to 13.8 (OR) times more likely to have malaria than children with normal platelet (Table 7).

A combination of thrombocytopaenia and anaemia with high sensitivity (80\%), specificity (84\%) and odds ratio (22) makes it the best predictor of malaria (Table $8)$. Children with this combination are 22 times more likely to have malaria than children without this combination. A combination of thrombocytopaenia and monocytosis, $(\mathrm{OR}=15)$ though not very specific for malaria is also a useful indicator of malaria.

\section{Discussion}

This study confirms that haematological abnormalities considered hallmark of malaria infection are common and more pronounced in $P$. falciparum malaria

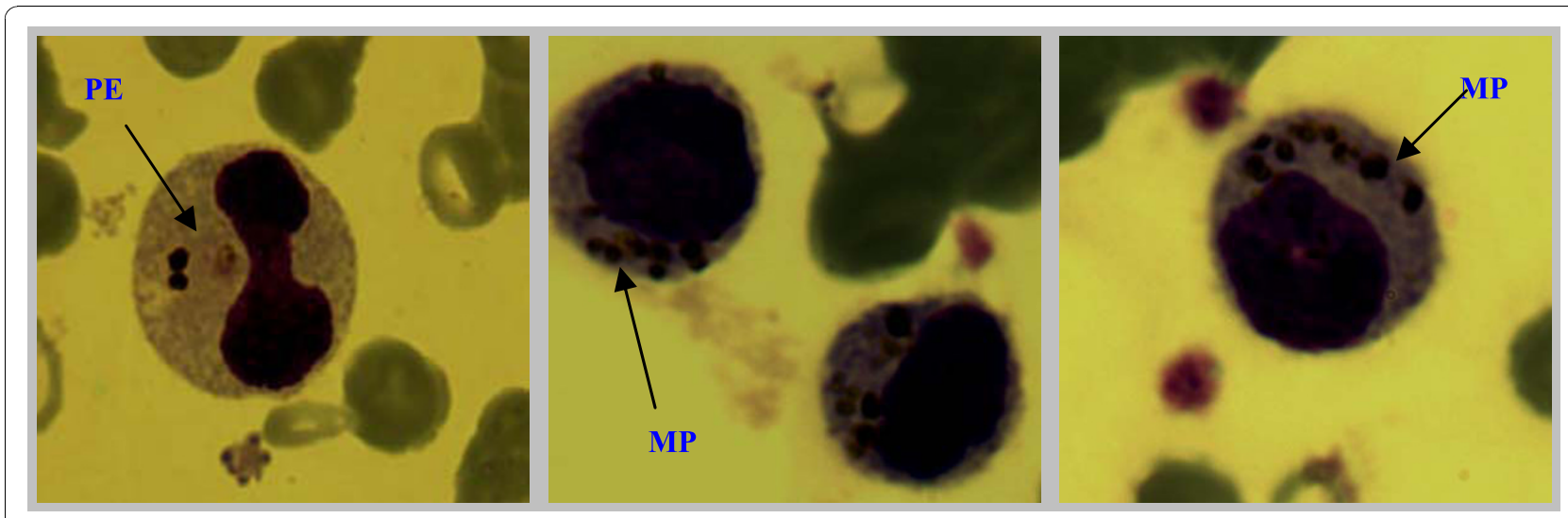

Figure 3 Monocytes containing malaria pigments (MP) and phagocytosis of parasitized erythrocytes (PE) 


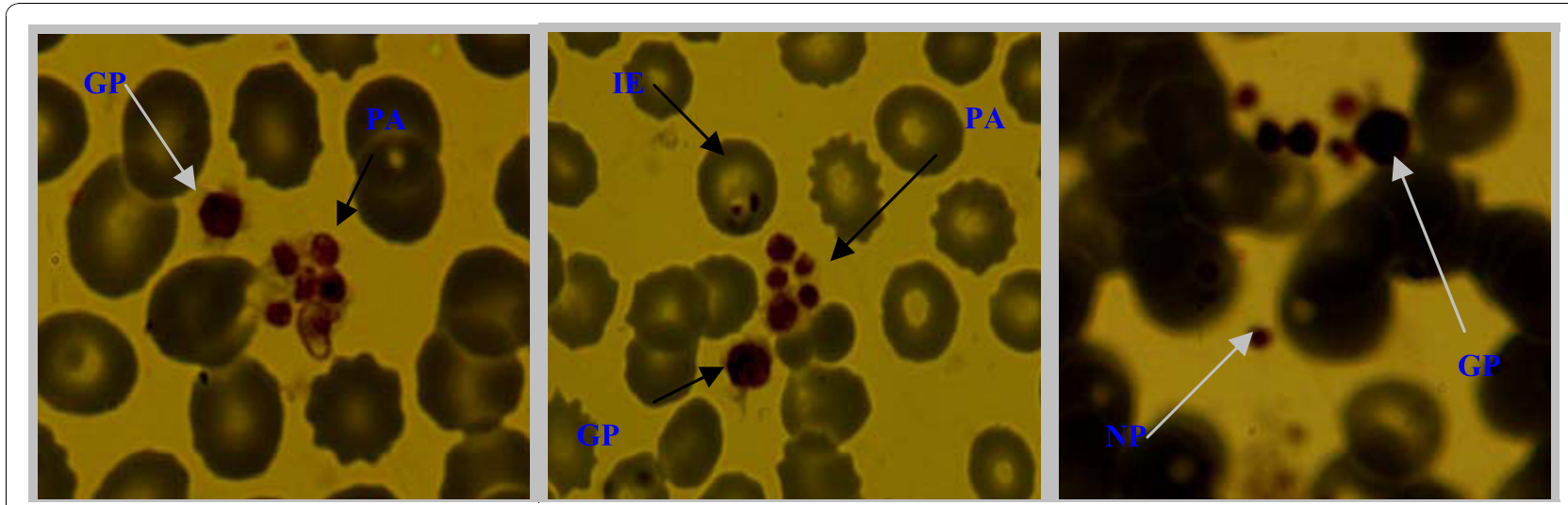

Figure 4 Small platelet aggregates (PA), giant platelets (GP), normal platelets (NP) and infected erythrocyte (IE) seen in anticoagulated blood.

infection, probably due to the higher levels of parasitaemia found in these patients. The abnormalities previously reported include changes in haemoglobin, leucocyte count, platelet abnormalities resulting in defective thromboplastin, and disseminated intravascular coagulation (DIC) $[8,11,14]$.

Anaemia is one of the most common complications in malaria especially in younger children and pregnant women in high transmission areas [15]. It is thought to result from a combination of haemolytic mechanisms and accelerated removal of both parasitized and nonparasitized red blood cells, depressed and ineffective erythropoiesis $[11,16,17]$. Abnormally high level of tumor necrosis factor (TNF), in malaria has been associated with marrow suppression [11] and imbalance in RBC surface markers such as CR1 [2].The present study, reports a significant reduction in $\mathrm{Hb}$ level in children infected with $P$. falciparum as compared to those not infected (Table 2). However, severe anaemia $(\mathrm{Hb}<5 \mathrm{~g} / \mathrm{dl})$ was only seen in a minority (3\%) of the children infected with malaria and none in the non-infected, most likely because this was a community-based study. The mild anaemia reported in $27 \%$ of the non-malaria infected children and some of the malaria-infected children may in part reflect poor nutritional status, background haemoglobinopathy, intestinal worm infestation and previous and/or repeated malaria infections in this area. Of these factors, haemoglobinophathies (HbAS, G6PD $\alpha^{-}$) could be the most important in the current study singly or in combination as shown in (Table 2) where $42 \%$ of the non-malaria infected children had one or more types of haemoglobinopathies compared to $25 \%$ of the non-anemic non-malaria infected children. Sickle cell trait incidence (28\%) [18] is common in Western Kenya. This compounded by high malaria transmission poses significant health problems in this region due to hereditary and acquired haemolytic anaemias although these children are protected from severe malaria disease.

In this study, although leucocytosis was frequently seen in the malaria-infected children, no significant difference in WBC was found between the two groups. In contrast, other studies have demonstrated leucopaenia $[3,7,19]$ or leucocytosis $[20,21]$. These findings are comparable with those of other studies $[17,22]$, which reported no significant difference in WBC between the malaria infected and non-infected groups. Monocytosis was the most important leukocytic change associated with malaria infection in this study with increased count being reported in the malaria infected group (median $1300 / \mu \mathrm{L}$ vs. $1020 / \mu \mathrm{L}, p<0.0001)$. Additionally monocyte count was positively associated with parasitaemia and negatively with age. The high monocyte count had been reported in patients with uncomplicated malaria [23] and subjects in this study also had uncomplicated malaria. However, this is in contrast to a previous study that reported low monocyte count being associated with

Table 5 Relationship between Platelet aggregate flag, platelet count

\begin{tabular}{llll}
\hline Platelet counts $\times 10^{3}$ & Patient Category & Samples in the Group & Samples with Platelet aggregate flag \\
\hline$<150$ & Malaria Negative & 16 & 3 \\
& Malaria Positive & 255 & 59 \\
$151-450$ & Malaria Negative & 356 & 13 \\
& Malaria Positive & 258 & 73 \\
$>450$ & Malaria Negative & 56 & 2 \\
& Malaria Positive & 10 & 1 \\
\hline
\end{tabular}


Table 6 Frequency of cold Agglutinin flag in the study groups

\begin{tabular}{lllll}
\hline Platelet count $\times 10^{3} / \mu \mathrm{L}$ & Patient category & samples in the group & Samples with cold agglutinin flag & (\%) \\
\hline$<150$ & Malaria Negative & 16 & 2 & 13 \\
& Malaria Positive & 255 & 112 & 44 \\
$150-450$ & Malaria Negative & 356 & 95 & 27 \\
& Malaria Positive & 258 & 113 & 44 \\
$>450$ & Malaria Negative & 56 & 31 & 55 \\
& Malaria Positive & 10 & 359 & 50 \\
Totals & & 951 & 38 \\
\hline
\end{tabular}

severe malaria and an adverse outcome [21]. None of these studies reported an association between monocyte count with parasitaemia or age. As previously reported $[17,21,23]$ children with malaria in this study had significantly high neutrophil count compared to the nonmalaria infected children. While low lymphocyte count is not uncommon in malaria $[3,11,14]$ the decrease in lymphocyte counts associated with malaria observed in this study are unusual. This finding may reflect redistribution of lymphocytes with sequestration in the spleen [11]. Lymphocytosis has also been reported elsewhere [21]. The observation of decreased eosinophil counts in this study is in agreement with previous studies [23,24]. This may suggest suppressed eosinophil production or release from the marrow or enhanced peripheral removal. There was no demonstrable relationship between leucocytosis, lymphocytopaenia or neutrophilia and parasite densities or age in this study. This may tend to support theory of host reaction to parasitaemia. Association between parasitaemia and haematological parameters should be interpreted with care because peripheral parasitaemia does not necessarily reflect the total body burden of parasites due to sequestered parasites, which still contribute to clinical manifestation [25].

Mononuclear cells, which are activated by Plasmodium during malarial attack, produce inflammatory cytokines, such as tumor necrosis factor (TNF), interleukin-1 and interleukin-6 (IL1, IL6). These cytokines stimulate the hepatic synthesis of acute phase inflammatory proteins, including CRP, which increase in malaria.
Phagocytosis of malaria pigments, infected and uninfected RBCs by monocytes, and neutrophils, has been observed in blood films of patients with malaria and is associated with disease severity $[16,11,21,23]$. The pigments are due to haemozoin from digested haemoglobin $[25,26]$. This study demonstrates that these changes occur early in the disease and not necessarily a marker of severe disease as some of the peripheral blood smears examined showed monocytes that contained malaria pigments and parasitized erythrocytes (Figure 3 and 4).

Platelet abnormalities in malaria are both qualitative and quantitative. In this study, platelet counts were significantly reduced in malaria-infected children. Thrombocytopaenia occurred in $49 \%$ of malaria cases and was inversely related to parasite density (Figure 2). Platelet count was the only parameter in the malaria-infected group that showed a decreasing trend across quartiles of parasite density (Table 4 ). Over $50 \%$ of the children with high parasitaemia ( $>10 \%$ ) had a platelet count of $<50,000 /$ uL. These observations imply that thrombocytopaenia may be a marker of parasite burden and disease severity. The association of platelet count and malaria has previously been described [23,27,28]. Two of our findings i.e., strong association with malaria and a trend across levels of parasite densities corroborates findings of a study of semi-immune population in Thailand [3]. Children with low platelet counts were also likely to have anaemia $(\mathrm{r}=0.2, p=0.0003)$ as previously reported from a study in Nigeria [20], which showed that baseline platelet counts were related to day twenty eight haematocrit, but no correlation between platelet

Table 7 Sensitivity, specificity, predictive value and odds ratio of the haematological parameters in diagnosis of malaria

\begin{tabular}{|c|c|c|c|c|c|c|}
\hline Variable & $\begin{array}{l}\text { Sensitivity* } \\
(95 \% \text { Cl) }\end{array}$ & $\begin{array}{l}\text { Specificity* }^{*} \\
(95 \% \text { Cl) }\end{array}$ & $\begin{array}{l}P P V^{*} \\
(95 \% \text { Cl) }\end{array}$ & $\begin{array}{l}N P V^{*} \\
(95 \% \text { Cl) }\end{array}$ & $\begin{array}{l}O R \\
(C I)\end{array}$ & $L R$ \\
\hline Platelets $<150000 / \mu \mathrm{L}$ & $90(86,95)$ & $61(57,66)$ & $69(64,73)$ & $86(84,89)$ & $13.8(7.2,24.8)$ & 2.3 \\
\hline $\mathrm{Hb}<10 \mathrm{~g} / \mathrm{dl}$ & $74(69,78)$ & $65(61,68)$ & $60(55,64)$ & $78(74,81)$ & $5(3.9,6.7)$ & 2.1 \\
\hline Monocytes count $>1500 / \mu \mathrm{L}$ & $74(67,79)$ & $54(50,57)$ & $38(35,43)$ & $84(80,87)$ & $3.34(2.5,4.6)$ & 1.6 \\
\hline Lymphocytes count $<2000 / \mu \mathrm{L}$ & $75(59,87)$ & $46(43,49)$ & $6(4,8)$ & $97(95,98)$ & $2.7(1.3,5.8)$ & 1.4 \\
\hline WBC $>17000 / u L$ & $70(56,81)$ & $46(43,49)$ & $8(6,1)$ & $96(93,98)$ & $2.1(1.1,3.7)$ & 1.3 \\
\hline Neutrophils count $>7500 / \mu \mathrm{L}$ & $72(60,82)$ & $38(34,42)$ & $10(7,12)$ & $93(90,96)$ & $1.6(0.9,2.8)$ & 1.2 \\
\hline
\end{tabular}

PPV- Positive Predictive Value, NPV-Negative Predictive value, LR- Likelihood ratio, *Percent, OR=odds ratio 
Table 8 Sensitivity, Specificity, Predictive value and Odds ratio for combination of haematological parameters in diagnosis of malaria

\begin{tabular}{|c|c|c|c|c|c|c|}
\hline Variable & $\begin{array}{l}\text { sensitivity* } \\
(95 \% \text { Cl) }\end{array}$ & $\begin{array}{l}\text { Specificity* } \\
(95 \% \mathrm{Cl})\end{array}$ & $\begin{array}{l}\mathrm{PPV}^{*} \\
(95 \% \mathrm{Cl})\end{array}$ & $\begin{array}{l}\text { NPV* } \\
(95 \% \mathrm{Cl})\end{array}$ & OR & LR \\
\hline Monocyte count $>1500 /$ LL\& Platelet $<150000 /$ uL & $99(86,99)$ & $43(39,47)$ & $12(9,15)$ & $98(97,99)$ & $15.3(5,49)$ & 1.68 \\
\hline Platelet count $<150000 / \mu \mathrm{L} \& \mathrm{Hb}<10 \mathrm{~g} / \mathrm{dl}$ & $80(72,86)$ & $84(76,91)$ & $86(78,92)$ & $78(69,85)$ & $22(12,45)$ & 5.2 \\
\hline $\mathrm{Hb}<10 \mathrm{~g} / \mathrm{dl} \&$ Monocyte count $>1500 / \mathrm{uL}$ & $82(75,87)$ & $44(40,48)$ & $28(24,32)$ & $90(86,93)$ & $3.6(2.4,5.6)$ & 1.47 \\
\hline
\end{tabular}

PPV- Positive Predictive Value, NPV-Negative Predictive value, OR- Odds ratio, LR Likelihood ratio *Values in percent

counts and parasite densities. A South Korean study reported correlation between thrombocytopenia and a higher degree of Plasmodium vivax parasitaemia and increased cytokine production [29]. In the present study not only was the mean platelet volume significantly higher in children with malaria but was also inversely related to platelet counts. Mean MPV increased as platelet count decreased in both malaria infected and noninfected children (Figure 1). This may reflect an early release of platelets from the bone marrow in response to reduced platelet level in the body. The raised MPV can be explained by the giant platelets observed in some of the peripheral blood smears examined (Figures 3 and $4)$.

Thrombocytopaenia seems to occur through peripheral destruction [21], excessive removal of platelets by splenic pooling $[19,30]$ as well as platelet consumption by the process of DIC [31]. This study confirms lack of bleeding in thrombocytopaenic malaria patients as previously reported [28]. Hypersensitive platelets, which are thought to enhance haemostatic responses, have been reported and may be the reason why bleeding episodes are rare in acute malaria infection, despite the thrombocytopaenia $[28,32,33]$. Reports of adequate or increased number of megakaryocytes in the bone marrow, makes decreased thrombopoiesis an unlikely cause of thrombocytopaenia in malaria [19]. Immune-mediated destruction of circulating platelets has been postulated as a cause of thrombocytopaenia seen in malaria. Platelets have also been shown to mediate clumping of $P$. falciparum infected erythrocytes [34]. This could lead to pseudo thrombocytopaenia. Malaria infected patients have elevated levels of specific IgG in their blood which binds to platelet-bound malaria antigens [33] possibly leading to accelerated destruction.

Platelet clumping was the most important platelet functional abnormality observed in this study. A large number of small platelets are seen mixed or clamped with a few giant platelets possibly due to the cytokine interference of megakaryopoiesis [35]. The findings in our study are consistent with these observations. Virtually all the peripheral blood smears from samples with platelet aggregate flag revealed small platelet aggregates mixed with giant platelets (platelets that approach or exceed the size of a red cell Figure 4), which most likely triggered the platelet aggregation. The platelets clumps made of groups of three to 12 platelets are falsely counted as single platelet by the analyzers thus causing pseudo-thrombocytopaenia. These observations suggest that, in as much as patients with malaria are likely to develop thrombocytopaenia, a reduced platelet count in some patients may be attributed in part to pseudothrombocytopaenia further explaining the lack of bleeding tendency. However, presence of giant platelets as well as increased MPV argues against pseudo-thrombocytopenia being the likeliest cause of thrombocytopaenia in malaria-infected individuals. Besides, a number of samples did not have microscopically detectable platelet aggregates despite having significant thrombocytopaenia. Giant platelets and increased MPV may indicate a compensatory premature release of platelets from the bone marrow [21] and would be consistent with true thrombocytopaenia occasioned by among others, peripheral destruction rather than pseudo-thrombocytopaenia.

Significantly more samples in the parasitaemic group had platelet aggregation suggesting that the aggregation was associated with malaria. However, when the data was stratified according to different platelet count ranges, a different pattern emerged suggesting that the platelet aggregation frequency was mainly related to platelet count rather than malaria infection status given that the number of thrombocytopaenic samples with the platelet aggregation in the malaria infected group increased in parallel with that of thrombocytopaenic samples in the non-malaria infected group (23\% Vs. $18 \%, p=0.6)$ Table 5. However this should be interpreted with caution as there were only 16 children in the noninfected group with thrombocytopaenia and this being a malaria endemic area you may not rule out some of them recovering from a previous malaria episode. The finding of 73 cases (28\%) in the malaria infected group with normal platelet counts having the platelet aggregation compared to only 13 samples $(3.6 \%)$ in the nonmalaria infected group further implies that this phenomenon may be largely related to malaria infection. The frequency of platelet aggregation was 8 times as higher in the malaria-infected children as opposed to noninfected group. This observation possibly rules out 
random factor related to the auto-analyzers or clots due to poor sampling technique as the causes of the flagging. Therefore, malaria infection is the most likely cause of either thrombocytopaenia or platelet aggregation. This is in agreement with findings of Scott et al[27]. there is no documented study so far that has established a clear cause of platelet clumping associated with malaria. Increased $C$ reactive protein (CRP) is an indicator of inflammation and is associated with malaria [36]. It is thought to be responsible for the platelet clumping. It has been observed that platelet dysfunction resulting in hyperaggregation occurs in association with malaria [37].

The auto-analyzer also detected cold agglutinins which was more common in samples from malaria-infected children (64\%) (Table 6). However, platelet count did not correlate to the presence of cold agglutinins as the proportions were comparable in those children with thrombocytopaenia and those with normal platelet count ( $42 \%$ vs. $36 \% \mathrm{p}=0.08)$. This study did not confirm the presence of the cold antibodies by a reference method such as Direct Coombs test (DAT) to determine their specificity or titers, however, it is assumed the cold agglutinins are related to malaria antigens binding to platelet-bound malaria antigens with the resultant platelet clumping observed... This may suggest an autoimmune reaction as another possible cause of malaria associated thrombocytopaenia. Elevated levels of platelet associated IgG have been observed in malaria patients with thrombocytopaenia [33]. A previous study in Gambian children [38] reported an association between high incidences DAT positivity and falciparum parasitaemia with raised antibody titers to falciparum schizonts. This is the first documentation to highlight the association of cold agglutinins as detected by haematology analyzers with malaria parasitaemia.

The present study demonstrates that low haemoglobin levels $(\mathrm{OR}=5)$ and low platelet counts $(\mathrm{OR}=13.8)$ are the two most reliable haematological parameters in predicting falciparum malaria in children from endemic areas. Children with thrombocytopaenia were 13.8 times more likely to have malaria than those with normal platelet count while anaemic children were 5 times more likely to have this outcome than non-anemic children. Thrombocytopaenia and anaemia with sensitivity of $90 \%$ and $74 \%$, specificity $61 \%$ and $65 \%$ respectively, would result in use of anti-malarial drugs in 35\%-39\% of malaria negative cases, but would only result in $10-26 \%$ of true malaria cases not being treated (Table 7). This is an error level for over-treatment that may be acceptable compared to presumptive clinical diagnosis currently practiced in most malaria endemic areas. The findings are consistent with other studies $[3,7,27,28]$, but none of these studies showed the predictive power of high monocyte count. This parameter with a sensitivity and specificity of $74 \%$ and $54 \%$ respectively had the best predictive value for malaria among all leucocytic cells. Children with increased monocyte count were three $(\mathrm{OR}=3)$ times more likely to have malaria than children with normal monocyte count. Low lymphocyte count, increased WBC and neutrophil counts had good sensitivities but lacked specificity to accurately diagnose malaria.

When haematological parameters were evaluated in combination, anaemia and thrombocytopaenia still had the greatest power in predicting malaria infection (Table 8). This study shows that a combination of low platelet count and $\mathrm{Hb}$ significantly increased the yield of diagnostic for malaria with sensitivity of $80 \%$, specificity $84 \%$. With this combination only $16 \%$ of malaria negative cases would receive anti-malarials and $20 \%$ of true malaria cases would not receive treatment. This combination also increases the probability of detecting malaria infection by up to 22 (95\% CL 12-45) times in children from malaria endemic regions. A combination of low platelet count and high monocyte count also had a significant diagnostic value (sensitivity $99 \%, \mathrm{OR}=15$ ). In this malaria endemic area, a combination of the three parameters irrespective of clinical parameters like fever should always be re-evaluated for malaria especially in children that are symptomatic but have low density parasitaemia resulting in a false negative blood smear or rapid diagnostic test.

In conclusion, infection with $P$ falciparum produces significant changes of haematological parameters in children living in malaria endemic regions. The most commonly affected parameters are platelets, haemoglobin, absolute monocyte counts and MPV. Thrombocytopaenia and monocytosis are associated with parasite density and, therefore, may be a marker of disease severity. The reduced platelet counts observed in some children may be related in part to pseudo-thrombocytopaenia but immune mediated thrombocytopaenia may not be ruled out. Although there was a trend towards platelet aggregation being associated with thrombocytopaenia but the frequency may still be primarily associated with malaria parasitaemia.

Presence of thrombocytopaenia in combination with anaemia and monocytosis in children from endemic areas may be useful as supportive diagnostic criteria for malaria in circumstances where definitive microscopic or RDT may be sub-optimal, as may be the case with low parasite density. Therefore, when used in addition to clinical and microscopy parameters, it can significantly improve malaria diagnosis and ideally prompt timely initiation of anti-malarial therapy. Further studies are required to characterize the cold agglutinins, platelet aggregates and explain their association with malaria. 
The large sample size used in this study gives this analysis power to detect differences between malaria infected and non-malaria infected cases. Limitations include lack of previous medical history including anti-malarial treatment for the non-infected cases, which could potentially affect the interpretation of the results. Additionally no further investigations were done to rule out other infections such as bacterial and viral that could produce such haematological alterations since diseases such as HIV are associated with thrombocytopenia [39]. However, the children were relatively clinically stable.

\section{Funding}

Study was funded by the PATH-Malaria Vaccine Initiative, the Malaria Vaccine Development Program of the U.S. Agency for International Development, and the US Army Medical Research and Materiel Command.

\section{Disclaimer}

The views of the authors do not necessarily reflect the position of the Kenya Medical Research Institute or the Department of the Army or the Department of Defense of USA.

\section{Acknowledgements \\ This publication has been made with the permission of the Director of the Kenya Medical Research Institute. \\ The authors are grateful to the dedication and enthusiasm of the "KEMRI/ WRP" Kombewa Clinic staff. We thank the children and parents of Kombewa Division who participated in the study. We specifically thank the clinical laboratory team. \\ This article has been published as part of Malaria Journal Volume 9 Supplement 3, 2010: Building Knowledge for Action: Proceedings of the 5th Multilateral Initiative on Malaria Pan-African Malaria Conference. The full contents of the supplement are available online at http://www. malariajournal.com/supplements/9/S3.}

\section{Author details}

${ }^{1}$ US Army Medical Research Unit-Kenya (Walter Reed Project), Nairobi, Kenya. ${ }^{2}$ Centre for Clinical Research, Kenya Medical Research Institute, Nairobi, Kenya. ${ }^{3}$ USAMRU-K (Walter Reed Project), Centre for Clinical Research, Kenya Medical Research Institute, P.O.Box 54- 40100, Kisumu, Kenya.

\section{Authors Contribution \\ RNM - coordinated specimen collection and analysis of clinical specimens, statistical analysis, manuscript writing and participated in study design. GH - participated in specimen collection and oversight for malaria microscopy. JW- coordinated $\mathrm{Hb}$ typing. DW, CG, LO and DJ participated in data analysis and manuscript writing. BRO Conceived the study, participated in study design, data analysis, manuscript writing and was the lead study investigator. All authors read and approved the final manuscript.}

\section{Competing interests}

None of the authors had conflict of interests in the results of the study.

Published: 13 December 2010

\section{References}

1. World Health Organization: World malaria report. Geneva; 2008.

2. Waitumbi JN, Opollo MO, Muga RO, Misore AO, Stoute JA: Red cell surface changes and erythrophagocytosis in children with severe Plasmodium falciparum anemia. Blood 2000, 95:1481-1486.
3. Erhart LM, Yingyuen K, Chuanak N, Buathong N, Laoboonchai A, Miller RS, Meshnick SR, Gasser RA Jr, Wongsrichanalai C: Hematological and clinical indices of malaria in a semi-immune population of Western Thailand. Am J Trop Med Hyg 2004, 70:8-14.

4. Barnish G, Bates I, Iboro J: Newer drug combinations for malaria. BMJ 2004, 328:1511-1512.

5. Hume JC, Barnish G, Mangal T, Armázio L, Streat E, Bates I: Household cost of malaria over diagnosis in rural Mozambique. Malar J 2008, 7:33.

6. World Health Organization: New perspective, malaria diagnosis. Geneva 2000.

7. Lathia TB, Joshi R: Can hematological parameters discriminate malaria from non malarious acute febrile illness in the tropics? Indian J Med Sci 2004, 58:239-244.

8. Reyburn H, Mbakilwa H, Mwangi R, Mwerinde O, Olomi R, Drakeley C, Whitty CJ: Rapid diagnostic tests compared with malaria microscopy for guiding outpatient treatment of febrile illness in Tanzania randomized trial. BMJ 2007, 334:403.

9. Wever PC, Henskens YM, Kager PA, Dankert J, Tom van Gool: Detectetion of imported malaria with the cell -Dyn 4000 Hematology analyzer. J Clin Microbiol 2002, 40:4729-4731.

10. Price RN, Simpson JA, Nosten F, Luxemburger C, Hkirjaroen, ter Kuile F, Chongsuphajaisiddhi T, White NJ: Factors contributing to anemia after uncomplicated falciparum malaria. Am J Trop Med Hyg 2001, 65:614-22.

11. Wickramasinghe $\mathrm{SN}$, Abdalla SH: Blood and bone marrow changes in malaria. In Bailliere's Clin Hematol. Volume 13. Harcourt Pub Ltd; 2000:277-299.

12. Ogutu BR, Apollo OJ, McKinney D, Okoth W, Siangla J, Dubovsky F, Tucker K, Waitumbi JN, Diggs C, Wittes J, Malkin E, Leach A, Soisson LA, Milman JB, Otieno L, Holland CA, Polhemus M, Remich SA, Ockenhouse CF, Cohen J, Ballou WR, Martin SK, Angov E, Stewart VA, Lyon JA, Heppner DG, Withers MR, MSP-1 Malaria Vaccine Working Group: Blood stage malaria vaccine eliciting high antigen specific antibody concentrations confers no protection to young children in Western Kenya. PLOS ONE 2009, 4: e4708.

13. Ministry of Health: National guidelines for diagnosis, treatment and prevention of malaria for health workers in Kenya. Division of Malaria Control Ministry of Health. Kenya; 2006.

14. Richards MW, Behrens RH, Doherty JF: Hematological changes in acute, imported Plasmodium falciparum malaria. Am J Trop Med Hyg 1998, 59:859.

15. Menendez C, Fleming AF, Alonso PL: Malaria-related anaemia. Parasitol Today 2000, 16:469-476.

16. Weatherall DJ, Miller LH, Baruch DI, Marsh K, Doumbo OK, Casals-Pascual C, Roberts DJ: Malaria and the red cell. Hematology Am Soc Hematol EduC Program 2002, 35-57.

17. Bashawri LA, Mandil AA, Bahnassy AA, Ahmed MA: Malaria: hematological aspects. Ann Saudi Med 2002, 22:372-376.

18. Aluoch JR: Higher resistance to Plasmodium falciparum infection in patients with homozygous sickle cell disease in Western Kenya. Trop Med Int Health 1997, 2:568-571.

19. Beale PJ, Cormack JD, Oldrey TB: Thrombocytopenia in malaria with immunoglobulin (IgM) changes. BMJ 1972, 1(5796):345-349.

20. Adedapo AD, Falade CO, Kotila RT, Ademowo GO: Age as a risk factor for thrombocytopenia and anaemia in children treated for acute uncomplicated falciparum malaria. J Vector Borne Dis 2007, 44:266-271.

21. Ladhani S, Lowe B, Cole AO, Kowuondo K, Newton CR: Changes in white blood cells and platelets in children with falciparum malaria: relationship to disease outcome. Br J Haematol 2002, 119:839-847.

22. Chiwakata CB, Hammer CJ, Dietrich M: High levels of inducible nitric oxide synthase mrna are associated with increased monocyte counts in blood and have a beneficial role in Plasmodium falciparum malaria. Infect Immun 2000, 68:394-399.

23. Abdalla SH: Peripheral blood and bone marrow leucocytes in Gambian children with malaria: numerical changes and evaluation of phagocytosis. Ann Trop Paediatr 1988, 8:250-258.

24. Davis TM, Ho M, Supanaranond W, Looareesuwan S, Pukrittayakamee S, White NJ: Changes in peripheral blood eosinophil count in falciparum malaria. Acta Trop 1991, 48:243-246.

25. Mujuzi G, Magambo B, Okech B, Egwang TG: Pigmented monocytes are negative correlates of protection against severe and complicated malaria in Ugandan children. Am J Trop Med Hyg 2006, 74:724-729. 
26. Hänscheid T, Egan TJ, Grobusch MP: Hemozoin: from melantonin pigment to drug target, diagnostic tool, and immune modulator. Lancet Infect Dis 2007, 7:675-685.

27. Scott CS, Van Zyl D, Ho E, Ruivo L, Mendelow B, Coetzer TL: Thrombocytopenia in patients with malaria: automated analysis of optical platelet counts and platelet clumps with the cell Dyn CD4000 analyzers. Clin Lab Haematol 2002, 24:295-302.

28. Gérardin P, Rogier C, Ka AS, Jouvencel P, Brousse V, Imbert P: Prognostic value of thrombocytopenia in African children with falciparum malaria. Am J Trop Med Hyg 2002, 66:686-691.

29. Park JW, Park SH, Yeom JS, Huh AJ, Cho YK, Ahn JY, Min GS, Song GY, Kim YA, Ahn SY, Woo SY, Lee BE, Ha EH, Han HS, Yoo K, Seoh JY: Serum cytokine profiles in patients with Plasmodium vivax malaria: a comparison between those who presented with and without thrombocytopenia. Ann Trop Med Parasitol 2003, 97:339-344.

30. Skudowitz RB, Katz J, Lurie A, Levin J, Metz J: Mechanisms of thrombocytopenia in malignant tertian malaria. BMJ 1973, 2:515-518.

31. Essien EM: The circulating platelet in acute malaria infection. $\mathrm{Br} J$ Haematol 1989, 72:589-590.

32. Kelton JG, Keystone J, Moore J, Denomme G, Tozman E, Glynn M, Neame PB, Gauldie J, Jensen J: Immune -mediated thrombocytopenia of malaria. J Clin Invest 1983, 71: 832-826.

33. Moulin F, Lesage F, Legros A-H, Maroga C, Moussavou A, Guyon P, Marc E, Gendrel D: Thrombocytopenia and Plasmodium falciparum malaria in children with different exposures. Arch Dis Child 2003, 88:540-541.

34. Pain A, Ferguson DJ, Kai O, Urban BC, Lowe B, Marsh K, Roberts DJ: Platelet-mediated clumping of Plasmodium falciparum-infected erythrocytes is a common adhesive phenotype and is associated with severe malaria. Proc Natl Acad Sci U S A 2001, 98:1805-1810.

35. Kelkar DS, Patnaik MM, Joshi SR: Malarial hematopathy. J Assoc Physicians India 2004, 52:611-612.

36. Verhoef $H$, West CE, Kraaijenhagen R, Nzyuko SM, King R, Mbandi MM, van Laatum S, Hogervorst R, Schep C, Kok FJ: Malarial anemia leads to adequately increased erythropoiesis in asymptomatic Kenyan children. Blood 2002, 100:3489-3494

37. Mohanty D, Marwaha N, Ghosh K, Sharma S, Garewal G, Shah S, Devi S, Das KC: Functional and ultrastructural changes of platelets in malarial infection. Trans R Soc Trop Med Hyg 1988, 82:369-375.

38. Facer CA: Direct Coombs antiglobulin reactions in Gambian children with Plasmodium falciparum malaria. II. Specificity of erythrocyte-bound IgG. Clin Exp Immunol 1980, 39:279-288.

39. Casals-Pascual C, Kai O, Newton CR, Peshu N, Roberts DJ:

Thrombocytopenia in falciparum malaria is associated with high concentrations of IL-10. Am J Trop Med Hyg 2006, 75:434-436.

doi:10.1186/1475-2875-9-S3-S4

Cite this article as: Maina et al: Impact of Plasmodium falciparum infection on haematological parameters in children living in Western Kenya. Malaria Journal 2010 9(Suppl 3):S4.

\section{Submit your next manuscript to BioMed Central and take full advantage of:}

- Convenient online submission

- Thorough peer review

- No space constraints or color figure charges

- Immediate publication on acceptance

- Inclusion in PubMed, CAS, Scopus and Google Scholar

- Research which is freely available for redistribution

Submit your manuscript at www.biomedcentral.com/submit
Biomed Central 